\title{
EDITORIAL
}

\section{Survivors of coarctation repair: fixed but not cured}

\section{S Celermajer, K Greaves}

Heart 2002;88:113-114

\begin{abstract}
While often considered to be cured, patients with repaired coarctation of the aorta frequently have premature morbidity and even mortality
\end{abstract}

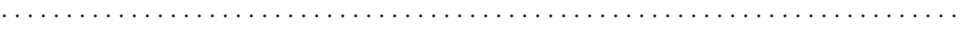

$S$ urgically repaired coarctation of the aorta (CoAo) is often regarded as a benign condition, in which the patient is essentially "cured". Consistent with this belief, life insurance companies often provide standard policies for young adults with postoperative CoAo, yet for the vast majority of other types of corrected congenital heart disease, individuals are either insurable only at high rates or not insurable at all. ${ }^{1}$

It has been recognised for many years, however, that patients with repaired CoAo frequently have premature morbidity and even mortality. Two long term studies of subjects who underwent repair in late childhood or young adult life reported that the mean age of death in such postoperative patients was only 38 years of age. ${ }^{23}$

Late problems after CoAo repair are principally caused by recoarctation, late aneurysm formation, hypertension and/or premature coronary, and cerebrovascular disease. Many (but not all) of the complications responsible for this poor outcome are consequences of mechanical problems at the site of repair. A relatively frequent problem is recurrent coarctation. A recent analysis of 11 studies which recruited 718 asymptomatic subjects who had undergone patch aortoplasty documented a recurrence rate of haemodynamically significant CoAo in up to $50 \%$ of survivors of neonatal repair and an overall recurrence rate of over 5\%. ${ }^{4}$ Accordingly, coarctation resection and end-to-end anastomosis (where possible) is now recommended as the repair of choice in the neonatal group. ${ }^{4}$

Late aneurysm formation has also been reported after every type of CoAo repair (end-toend, subclavian flap, and patch aortoplasty), with rupture of such aneurysms being responsible for approximately $7 \%$ of all deaths. ${ }^{2}$ Late aneurysm formation is particularly prevalent following Dacron patch repair, a technique commonly employed 10-20 years ago, being utilised in over $10 \%$ of cases. ${ }^{4}$ Resection of the coarctation ridge may predispose to local aneurysm formation, and the use of Dacron material itself may also contribute to late aortic dilation, as the graft material itself may undergo stretching and/or deterioration..$^{4-6}$ Furthermore, late aneurysm formation in the ascending aorta, proximal to the surgical repair site, has also been noted as a late complication. ${ }^{7}$ david@

card.rpa.cs.nsw.gov.au

.............................

\section{COMPLICATIONS FOLLOWING SATISFACTORY REPAIR}

In addition, major complications may arise even in the presence of a structurally satisfactory repair. There is a high frequency of accelerated coronary artery disease in repaired CoAo subjects with up to one third of all late deaths occurring from acute myocardial infarction. ${ }^{28}$ Cerebrovascular accidents are a cause of death in approximately $7 \%$ of patients, either due to hypertension or to a ruptured aneurysm of the circle of Willis, an associated abnormality in approximately $10 \%$ of CoAo patients. ${ }^{239}$ Bicuspid aortic valve occurs with a reported incidence of up to $85 \%$, necessitating replacement in approximately $5 \%$ of patients. This figure may be conservative, however, being limited by the study follow up period. $^{23}$

Much attention has focused on the role of upper body hypertension after CoAo repair, as this is associated with a significant proportion of the late morbidity and mortality in this group. Depending on the series reviewed and definition used, up to three quarters of all patients with repaired CoAo will have systemic hypertension by 20-30 years after operation. ${ }^{2}{ }^{10}$ However, the mean age of CoAo repair in these early series was relatively high-between 10 and 20 years of age-and subgroup analysis suggested that earlier repair might be associated with a lower prevalence and/or less severe late hypertension. In a study of 226 patients undergoing coarctation repair before and after the age of 20 years, Presbitero reported that $30 \%$ and $60 \%$ were hypertensive at 20 year follow up, respectively. ${ }^{3}$ Similarly, in a study of 571 patients, Cohen and colleagues showed that late hypertension occurred in $7 \%$ of those operated on as infants $(<1$ year of age) as opposed to $33 \%$ who had undergone repair after the age of 14 years. $^{2}$ Consistent with these findings, Brouwer and colleagues speculated that the optimal age for elective surgery was 18 months, since this age group showed the best results with respect to restenosis, normal blood pressure, and life expectancy. ${ }^{10}$

In order to investigate whether early repair does indeed reduce the propensity to develop late onset hypertension, in this issue of Heart O'Sullivan and colleagues report on 119 children who underwent CoAo repair early, at age 2-3 months, and had comprehensive blood pressure measurements taken $7-16$ years later. ${ }^{11}$ The results were compared with 1034 normal children aged 6-16 years. These investigators found that $28 \%$ of all patients had hypertension at rest or during normal ambulation, including $21 \%$ of those who had no evidence of residual aortic 
obstruction. In this large series of carefully investigated patients there was therefore a disappointingly high proportion that still developed significant hypertension, despite early "successful" repair. Furthermore, the values for development of hypertension in this study may represent an underestimate, as the follow up period was relatively short compared with other studies. ${ }^{23}$ In addition, O'Sullivan and colleagues did not study blood pressure responses to exercise in these children, and it is well recognised that up to $20 \%$ of patients who have undergone successful CoAo repair may develop severe hypertension on exercise, in spite of normal resting blood pressure. $^{1213}$

\section{PATHOPHYSIOLOGY}

The pathophysiology of hypertension after coarctation repair is not fully understood. Restenosis or residual stenosis accounts for only a minority of cases of postoperative hypertension, as evidenced by the report described in this issue. There are two hypotheses advanced to explain this observation: either CoAo may be a manifestation of a generalised vascular abnormality, or CoAo may produce an effect on the "upstream" vasculature before repair, that is not completely reversible in some subjects. This latter theory is favoured by evidence from Gidding and others, who have demonstrated that infusion of noradrenaline (norepinephrine) into the brachial artery had a three times greater effect on forearm vascular resistance in CoAo repair patients than in a control group with mild hypertensive heart disease. ${ }^{14}$ By contrast, there was no difference in calf vessel responses between the CoAo and control groups. Similarly Gardiner and colleagues, measuring vascular function in both the brachial and femoral arteries in normotensive patients with repaired CoAo, demonstrated abnormal small and large vessel function in the "pre-coarctation" arm vessels but normal responses in "post-coarctation" leg vessels. ${ }^{13}$ In the latter study, abnormal vascular responses were not related to age at operation and were found even in subjects who had undergone repair in the neonatal period. This suggests that late arterial function may be influenced by very early hypertension related changes in the vessel walls.

In vitro evidence supporting this view also comes from the comparison of vascular tissue from pre-coarctation and post-coarctation vascular beds, with upstream vessels showing increased rigidity, more collagen, less smooth muscle, and greater contractility in response to potassium, noradrenaline, and prostaglandin F2 $\alpha .{ }^{15}$ Furthermore, animal models of coarctation show significantly decreased nitric oxide bioavailability above the stricture, whereas concentrations below remain normal, again suggesting that the abnormality lies in the upstream vascular bed and is not related to circulating humoral factors. ${ }^{16}$

\section{CLINICAL IMPLICATIONS}

There are several clinical implications from these data. Ideally, patients who have had CoAo repair require ongoing surveillance on an annual basis. Physical signs regarding the presence and severity of aortic stenosis or regurgitation should be assessed, in view of the high prevalence of coexisting bicuspid aortic valve. Absent, diminished, or delayed femoral pulses may indicate recurrence of coarctation. In our practice, we perform transthoracic echocardiography every second year for interrogation of left ventricular wall thickness, aortic valve function, and the coarctation repair site. Regarding the latter, the descending aorta should be assessed for patency, systolic flow velocity by Doppler techniques (normally $<2.5 \mathrm{~m} / \mathrm{s}$ ) and an absence of diastolic flow, which would suggest the absence of important recoarctation. If Dacron patch aortoplasty was used, we perform chest $x$ ray every two years, and computed tomography or magnetic resonance imaging every five years, to exclude late aneurysm formation.

For the detection of hypertension, yearly supine and alternate yearly exercise blood pressure measurements should be undertaken as part of routine surveillance. Evidence regarding treatment guidelines is sparse in this clinical setting, but our practice is to treat persistent resting hypertension of $\geqslant 140 / 90 \mathrm{~mm} \mathrm{Hg}$, and to consider pharmacological treatment (with $\beta$ blockers) even in subjects normotensive at rest, if the systolic blood pressure exceeds $200 \mathrm{~mm} \mathrm{Hg}$ at low levels of exercise on treadmill testing. Ambulatory 24 hour blood pressure measurement, as reported by $\mathrm{O}^{\prime}$ Sullivan's group, is appealing. ${ }^{11}$ However, this technique is not always available, can be difficult for the young adult patient, and the diagnostic value of the results remain unclear.

Patients with repaired coarctation of the aorta, therefore, may be "fixed" but are often not cured. It may be difficult to persuade asymptomatic adolescents and young adults to attend for regular medical check ups, but the cost for failure in this regard may be high. Careful clinical and imaging follow up, with appropriate and early intervention, may save lives in this group of subjects, even in those who have been "completely" repaired in the first year of life.

\section{Authors' affiliations}

D S Celermajer, K Greaves, Department of Cardiology, Royal Prince Alfred Hospital, Sydney, Australia.

\section{REFERENCES}

1 Celermajer DS, Deanfield JE. Employment and insurance for young adults with congenital heart disease. Br Heart J 1993;69:539-43.

2 Cohen M, Fuster V, Steele PM, et al. Coarctation of the aorta. Long-term follow-up and prediction of outcome after surgical correction. Circulation 1989:80:840-5

3 Presbitero $\mathbf{P}$, Demarie $D$, Villani $M$, et al. Long term results (15-30 years) of surgical repair of aortic coarctation. Br Heart J 1987;57:462-7.

4 Backer CL, Paape K, Zales VR, et al. Coarctation of the aorta. Repair with polytetrafluoroethylene patch aortoplasty. Circulation 1995:92: $11132-6$

5 Hehrlein FW, Mulch J, Rautenburg HW, et al. Incidence and pathogenesis of late aneurysms after patch graft aortoplasty for coarctation. J Thorac Cardiovasc Surg 1986;92:226-30.

6 Lundqvist B, Almgren B, Bowald S, et al. Deterioration and dilatation of Dacron prosthetic grafts. Acta Chir Scand Suppl 1985;529:81-5.

7 Heikkinen LO, Ala-Kulju KV, Salo JA. Dilation of ascending aorta in patients with repaired coarctation. Scand J Thorac Cardiovasc Surg $1991 ; 25: 25-8$.

8 Maron BJ, Humphries JO, Rowe RD, et al. Prognosis of surgically corrected coarctation of the aorta. A 20-year postoperative appraisal. Circulation 1973:47:1 19-26.

9 Edwards JE, Carey LS, Neufeld HN, et al. Congenital heart disease. Philadelphia: WB Saunders, 1965:692

10 Brouwer RM, Erasmus ME, Ebels T, et al. Influence of age on survival, late hypertension, and recoarctation in elective aortic coarctation repair. Including long-term results after elective aortic coarctation repair with a follow-up from 25 to 44 years. J Thorac Cardiovasc Surg follow-up from 25 to 44.

11 O'Sullivan JJ, Derrick G, Darnell R. Prevalence of hypertension in children after early repair of coarctation of the aorta: a cohort study using casual and 24 -hour blood pressure measurement. Heart 2002;88:163-6.

12 Simsolo R, Grunfeld B, Gimenez M, et al. Long-term systemic hypertension in children after successful repair of coarctation of the aorta. Am Heart J 1988;115:1268-73.

13 Gardiner HM, Celermajer DS, Sorensen KE, et al. Arterial reactivity is significantly impaired in normotensive young adults after successful repair of aortic coarctation in childhood. Circulation 1994;89:1745-50.

14 Gidding SS, Rocchini AP, Moorehead C, et al. Increased forearm vascular reactivity in patients with hypertension after repair of coarctation. Circulation 1985:71:495-9.

15 Sehested J, Baandrup U, Mikkelsen E. Different reactivity and structure of the prestenotic and poststenotic aorta in human coarctation. Implications for baroreceptor function. Circulation 1982;65:1060-5.

16 Barton CH, Ni Z, Vaziri ND. Enhanced nitric oxide inactivation in aortic coarctation-induced hypertension. Kidney Int 2001;60:1083-7. 